\title{
Five monogenean species (Allodiscocotylidae, Heteromicrocotylidae, Microcotylidae) from the Pacific seabream Acanthopagrus pacificus (Perciformes: Sparidae) in the Gulf of Tonkin off Vietnam, with descriptions of three new species
}

\author{
Ha Van Nguyen ${ }^{1}$, Hung Manh Nguyen ${ }^{1,6^{*}}$, Ngo Duy Ha ${ }^{1}$, Chinh Nguyen Ngoc ${ }^{1}$, Thanh Bui Ngoc ${ }^{2}$, Sinh Xuan Le ${ }^{3}$, \\ Yulia Tatonova $^{4}$ and Stephen E. Greiman ${ }^{5}$ \\ ${ }^{1}$ Institute of Ecology and Biological Resources, Vietnam Academy of Science and Technology, Cau Giay, Hanoi, Vietnam; \\ ${ }^{2}$ Research Institute for Aquaculture No. 1, Dinh Bang, Tu Son, Bac Ninh province, Vietnam; \\ ${ }^{3}$ Institute of Marine Environment and Resources, Ngo Quyen, Hai Phong, Vietnam; \\ ${ }^{4}$ Federal Scientific Center of the East Asia Terrestrial Biodiversity, Far Eastern Branch, Russian Academy of Sciences, Vladivostok, Russia; \\ ${ }^{5}$ Georgia Southern University, Statesboro, United States of America \\ ${ }^{6}$ Graduate University of Science and Technology, Vietnam Academy of Science and Technology, Cau Giay, Hanoi, Vietnam.
}

\begin{abstract}
A total of 52 specimens of the Pacific seabream Acanthopagrus pacificus Iwatsuki, Kume et Yoshino from the Gulf of Tonkin off Vietnam were examined for monogeneans. Twenty fish were parasitised by 101 individuals of five monogenean species, including two known species Allodiscocotyla diacanthi Unnithan, 1962 and Heterapta chorinemi (Tripathi, 1956), as well as three new species, Polylabroides tienyenensis sp. n., Polylabroides tonkinensis sp. n. and Metacamopia lebedevi sp. n. Polylabroides tienyenensis and P. tonkinensis are morphologically more similar to Polylabroides guangdongensis Zhang et Yang, 2001 in comparison with other species within the genus, based on the absence of small spines on the cirrus. However, P. tonkinensis is distinguished from $P$. guangdongensis by fewer clamps on the haptor and by the different shapes of the large spines on the cirrus. Similarly, P. tienyenensis differs from P. guangdongensis by vaginal ducts with fewer branches, fewer clamps and smaller egg size. Metacamopia lebedevi is distinguished from Metacamopia chorinemi (Yamaguti, 1953) by the arrangement of testes (one row vs two rows), diverticula absent in the oesophagus, and the number of anchor pairs (one $v s$ two); it differs from Metacamopia oligoplites Takemoto, Amato et Luque, 1996 by the smaller haptor, shape and absence of small sclerotised hooks, the number of ribs in their clamps, and the position of the testes; it can be separated from Metacamopia indica (Unnithan, 1962) by having fewer testes and lacking sclerotised structures in the vagina. The present study also provides the measurements for A. diacanthi, H. chorinemi, and proposes a new key to all species of Polylabroides.
\end{abstract}

Keywords: Polyopisthocotylea taxonomy, Monogenea, marine parasites, sparids, western Pacific

The Pacific seabream, Acanthopagrus pacificus Iwatsuki, Kume et Yoshino (Perciformes: Sparidae), is distributed throughout the western Pacific (Iwatsuki et al. 2010). Hitherto, there are no records of monogeneans from $A$. pacificus. However, 37 monogenean species have been recorded from fishes of Acanthopagrus spp., including one species of Haliotrema Johnston et Tiegs, 1922 (Johnston and Tiegs 1922, Roubal 1981, Byrnes 1986a); one species of Murraytrema Price, 1937 (Zhang and Yang 2001); one species of Encotyllabe Diesing, 1850 (Yamaguti 1934, Nitta and Nagasawa 2015); one species of Lobotrema Tripathi, 1959 (Yamaguti 1958, Roubal 1981, Byrnes 1986a, Nitta and
Nagasawa 2015); one species of Pseudaxine Parona et Perugia, 1890 (Chauhan 1945); one species of Aspinatrium Yamaguti, 1963 (Yamaguti 1963); one species of Microcotyle van Beneden et Hesse, 1863 (Ko and Chan 2002); one species of Udonella Johnston, 1835 (Byrnes 1986a); two species of Euryhaliotrema Kritsky et Boeger, 2002 (Ogawa and Egusa 1978a, Kritsky and Boeger 2002, Kritsky 2012); two species of Anoplodiscus Sonsino, 1890 (Yamaguti 1958, Ogawa and Egusa 1981, Roubal 1981, Byrnes 1986a, Maran et al. 2014); two species of Benedenia Diesing, 1858 (Byrnes 1986a, Hussey 1986); four species of Polylabris Euzet et Cauwet, 1967 (Mamaev and Parukhin 
1976, Ogawa and Egusa 1980, Hussey 1986, Al-Daraji et al. 2010); eight species of Polylabroides Mamaev et Parukhin, 1976 (Murray 1931, Yamaguti 1963, Mamaev and Parukhin 1976, Roubal 1981, Byrnes 1985, Dillon et al. 1985, Mamaev 1988, Zhang and Yang 2001) and one species of Lamellodiscus Johnston et Tiegs, 1922 (Johnston and Tiegs 1922, Ogawa and Egusa 1978b, Roubal 1981, Byrnes 1986b, Kritsky 2012, Nitta and Nagasawa 2015, Zhang et al. 2018). Species of the polyopisthocotylean genera Metacamopia Lebedev, 1972, Allodiscocotyla Yamaguti, 1953, and Heterapta Unnithan, 1961, have never been reported from fishes of the genus of Acanthopagrus Peters.

Among the monogenean fauna of marine fishes in Vietnam, Metacamopia and Allodiscocotyla have been found infecting different carangid hosts, e.g. Metacamopia indica (Unnithan, 1962) in Scomberoides lysan (Forsskål) (Lebedev 1972, 1986); Metacamopia chorinemi (Yamaguti, 1953) in S. lysan and Selar crumenophthalmus (Bloch) (Lebedev 1970, 1986); Allodiscocotyla chorinemi Yamaguti, 1953 in S. lysan, Caranx sp., and Decapterus sp. (Lebedev 1970); Allodiscocotyla diacanthi Unnithan, 1962 in Decapterus sp. (Lebedev 1970). There are no previous records of species of Heterapta and Polylabroides Mamaev et Parukhin, 1976 from the coast of Vietnam.

This study is the first survey of monogeneans from the Pacific seabream, A. pacificus, in the Gulf of Tonkin, off Vietnam. Herein, we present the description of one new species of Metacamopia and two new species of Polylabroides, as well as new host records and measurement for A. diacanthi and H. chorinemi (Tripathi, 1956).

\section{MATERIAL AND METHODS}

During a survey of the helminth fauna of marine fishes off the coast of Vietnam between March 2012 and May 2018, we examined 52 individuals of Acanthopagrus pacificus collected from five locations in the Gulf of Tonkin, e.g. off Mong Cai $(21.4463 \mathrm{~N}$, 107.9438E), Tien Yen (mangrove forest) (21.3052N, 107.4736E), Quat Lam (20.2016N, 106.3888E), Do Son (20.7211N, 106.7980E), and Cat Ba (20.7252N, 107.0463E).

Fish were purchased alive from fishermen, placed in an ice box and carried fresh to the laboratory. All fishes were euthanised using benzocaine ( $100 \mathrm{mg} / \mathrm{l})$ within 12 hours before examination. Gills were cut out and gill lamellae were placed separately in Petri dishes with seawater and checked for the presence of monogeneans under an Olympus SZ61 stereomicroscope. Monogeneans were removed from gill filaments and debris with the aid of fine brushes and needles, fixed in hot $\left(70^{\circ} \mathrm{C}\right) \mathrm{AFA}$ (a mixture of $70 \%$ ethanol-formalin-acetic acid in the ratio of $90: 7: 3$ ), and preserved in $70 \%$ ethanol. After one month, half of samples was stained with Mayer's carmine while the other half was stained with Gomori's trichrome. Then all samples were dehydrated using an ethanol series (80-100\%), cleared in xylene and mounted in Canada balsam.

The morphological characters of monogeneans were studied using an Olympus BX53 light microscope at magnifications ranging from $40 \times$ to $1,000 \times$; and drawings were made with the aid of a camera lucida. All measurements are given in micrometres presenting the range followed by the mean and the number of individuals or structures measured in parentheses.

Type specimens and vouchers are deposited at the Department of Parasitology, Institute of Ecology and Biological Resources, and in the Vietnam National Museum of Nature, Hanoi, Vietnam.

\section{RESULTS}

Twenty individuals of Acanthopagrus pacificus were infected by a total of 101 monogenean specimens. The intensity of infection varied from 1 to 16 worms per fish. Morphological examination of all 101 monogenean specimens revealed that they represented five species. Among them, one dominant species consisted of 95 specimens, while the other four species consisted of only one or two specimens each/species. The details of each species are presented below.

\section{Polylabroides tienyenensis sp. n.}

Figs. 1, 2

\section{ZooBank number for species:} urn:Isid:zoobank.org:act:38F13E50-5B5E-413A-AD0A-3BA560F57545.

Description (based on one specimen stained in Mayer's carmine and one specimen stained in Gomori's trichrome)

Body elongate, subcylindrical, tapering anteriorly and posteriorly, 3.362-3.875 in length, maximum width at level of ovary 205-287. Anterior extremity with three slight protuberances in which cephalic glands open. Haptor symmetrical, distinctly delineated from body proper, armed with 31-36 pairs of clamps (Fig. 1A). Clamps of typical $M i$ crocotyle-type without accessory sclerite (Figs. 1E, 2C,D), similar in shape, dissimilar in size; the largest clamps in anterior region of haptor, 66-68 × 30-43 $(67 \times 37)(\mathrm{n}=8)$; middle clamps 64-66 × 31-37 $(65 \times 34)(\mathrm{n}=8)$; posterior clamps $41 \times 25-31(41 \times 28)(\mathrm{n}=8)$.

Buccal suckers two, muscular, oval, without septa, 53$57 \times 47-49(55 \times 48)(\mathrm{n}=4)$. Mouth ventro-subterminal; pharynx subglobular, 39-41 in width (Fig. 1B). Oesophagus slender, 230 in length, bifurcating at posterior end of cirrus, about 272 from anterior extremity. Intestinal caeca two, extending posteriorly but does not enter haptor; right and left caeca equal in length.

Testes 13, postovarian, globular or elongate-oval, large, dissimilar in size, $62-102 \times 66-120(88 \times 92)(n=24)$; arranged in longitudinal intracaeca row (Fig. 1A). Vas deferens dilating with sperm at base, winding sinuously forward along midline of body, entering at posterior end of cirrus. Genital atrium at prebifurcal, thin walled, oval, $62 \times 51$ and $68 \times 51$ in size. Cirrus spherical, $37 \times 41$ and $41 \times 49$ in size, armed with two large spines, 39-41 (40) long $(n=4)$. Cirrus spines elephant's tusk-shaped with rounded base (Figs. 1C, 2A,B).

Ovary pretesticular, question mark-shaped, intercaecal, equatorial. Seminal receptacle well-defined, round, lies close to distal end of ovary. Oötype mid-ovarian, oval, surrounded by Mehlis'glands, two times smaller than seminal receptacle, connected with genito-intestinal canal (Fig. 1D). Vaginal aperture median, ventral, postbifurcal, about 328 from anterior margin of body. Two narrow vagi- 
A

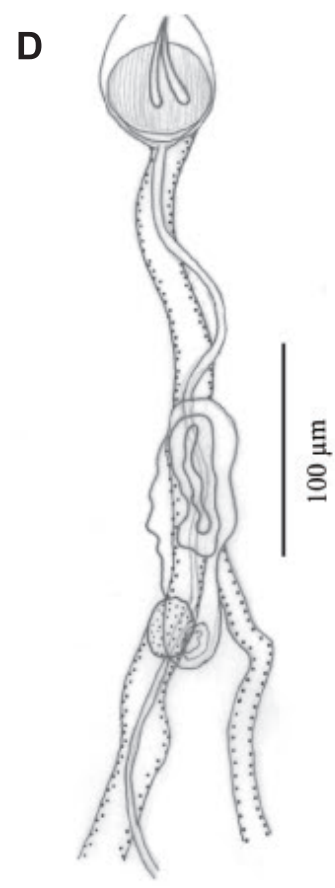

E

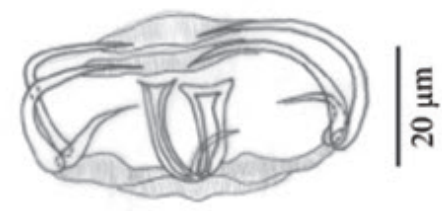

B

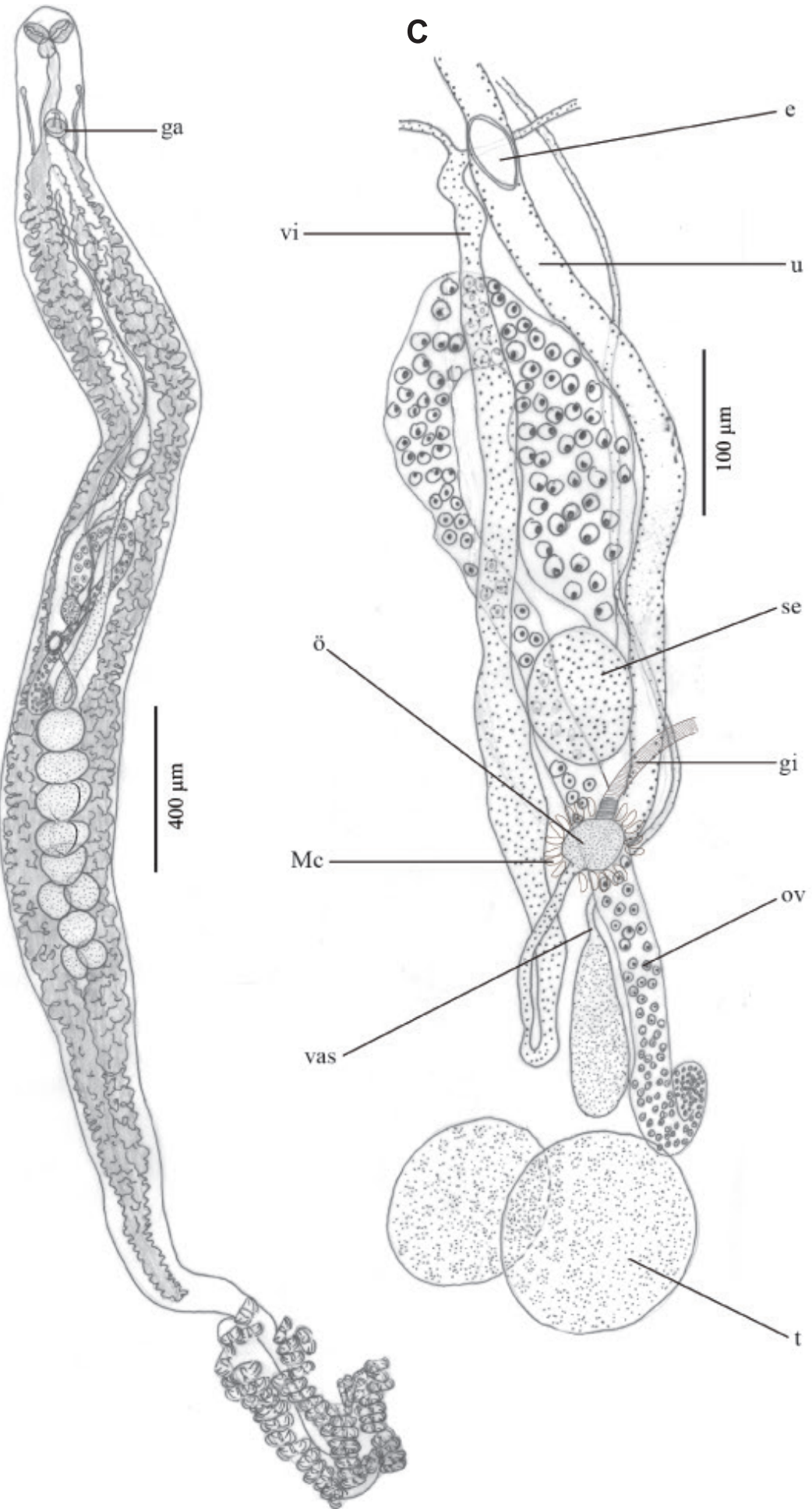

Fig. 1. Polylabroides tienyenensis sp. n. from Acanthopagrus pacificus Iwatsuki, Kume et Yoshino. A - head region; B - holotype, total view; C - reproductive system; D - cirrus and vagina; E - clamp. Abbreviations: e - egg; ga - genital atrium; gi - genito-intestinal canal; Mc - Mehlis' glands; ö - oötype; ov - ovary; $\mathrm{t}$ - testis; $\mathrm{u}$ - uterus; vas - vas deferens; vi - duct of vitelline reservoir duct.

nal ducts lateral to vagina, embracing intestinal caeca, then connected dorsally, extend backward and again divide before opening into branches of Y-shaped vitelline duct. Vitellarium follicular, coextensive with caeca; common duct joining oötype. Uterus arising from dextral margin of oötype, extends forward and opens at vaginal aperture. Only one small egg in uterus observed; egg ovoid, $50 \times 25$ in size, with filaments at both ends.
Type host: Acanthopagrus pacificus Iwatsuki, Kume et Yoshino.

Type locality: Gulf of Tonkin, off Tien Yen district, Quang Ninh province, Vietnam $\left(21.305278^{\circ} \mathrm{N}, 107.473611^{\circ} \mathrm{E}\right)$.

Site of infection: Gills.

Prevalence and intensity of infection: $2 \%$ $(\mathrm{n}=52)$; and 2 specimens/fish.

Type material: Holotype (NMH-Microcotylid-2015-1) 

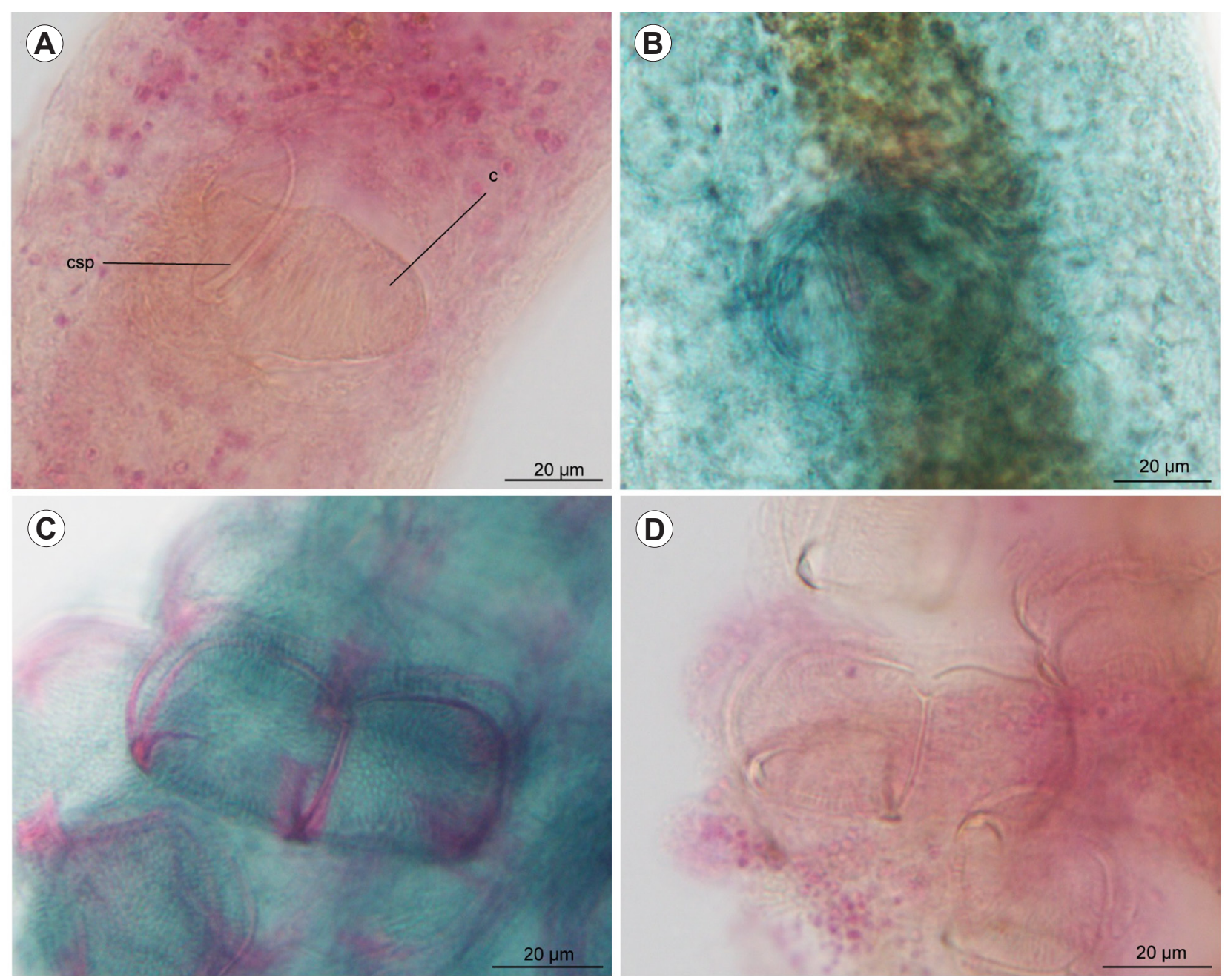

Fig. 2. Polylabroides tienyenensis sp. n. from Acanthopagrus pacificus Iwatsuki, Kume et Yoshino. A - clampcirrus (specimen stained with Mayer's carmine); B - cirrus (specimen stained with Gomori's); C - clamp (specimen stained with Gomori's); D - clamp (specimen stained with Mayer's carmine). Abbreviations: c - muscular base; csp - cirrus spines.

is deposited in the Department of Parasitology, Institute of Ecology and Biological Resources and one paratype (NMHMicrocotylid-2015-2) is deposited in the Vietnam National Museum of Nature, Hanoi, Vietnam.

Ety mology: The specific name refers to the type locality of the parasite (Tien Yen District).

Remarks. Polylabroides consists of eight species and can be divided into two groups based on the number of large spines on the cirrus (Zhang and Yang 2001). The first group comprises two taxa with numerous large spines on the cirrus; i.e. Polylabroides quadruspinosus Byrnes, 1985 (4 large spines) and Polylabroides longispinosus Byrnes, 1985 (40-67 large spines). The second group comprises taxa with only two large spines on the cirrus and includes $P$. tienyenensis sp.n. The new species differs from Polylabroides australis (Murray, 1931), Polylabroides biungulatus Mamaev et Parukhin, 1976, Polylabroides mylionis Dillon, Hargis et Harrises, 1985, Polylabroides multispinosus Roubal, 1981, and Polylabroides zini Mamaev, 1988 by the absence of small spines on the cirrus. Polylabroides tienyenensis most resembles Polylabroides guangdongensis Zhang et Yang, 2001 in the structure of the genital atrium and cirrus (no small spines; two large spines are straight, curved only at distal end), as well as the number of testes (approximately 13). However, P. tienyenensis can be distinguished from the latter species by the narrower body (width $246 \mu \mathrm{m} v s 453 \mu \mathrm{m}$ ), fewer clamps (62-72 vs 96-106) and smaller eggs much $(50 \times 25 \mu \mathrm{m} v s 205 \times 68$ $\mu \mathrm{m})$. This is the first Polylabroides species described from A. pacificus in the coast of Vietnam.

\section{Polylabroides tonkinensis sp. n.}

Figs. 3, 4

\section{ZooBank number for species:}

urn:lsid:zoobank.org:act:B9B48B88-5BF9-4F54-9903-E9FE10D53207.

Description (based on selected, stained and measured 36 specimens, from totally collected 95 specimens, including 18 specimens stained in Mayer's carmine and other 18 specimens stained in Gomori's trichrome).

Body elongate, subcylindrical, 2.38-2.81 mm (2.63 $\mathrm{mm} ; \mathrm{n}=12)$ in length, maximum width 233-394 (310; $\mathrm{n}=20$ ) at level of ovary, tapering anteriorly and posteriorly. Haptor symmetrical, distinctly delineated from body proper, armed with $30-40(36 ; n=12)$ pairs of clamps. 

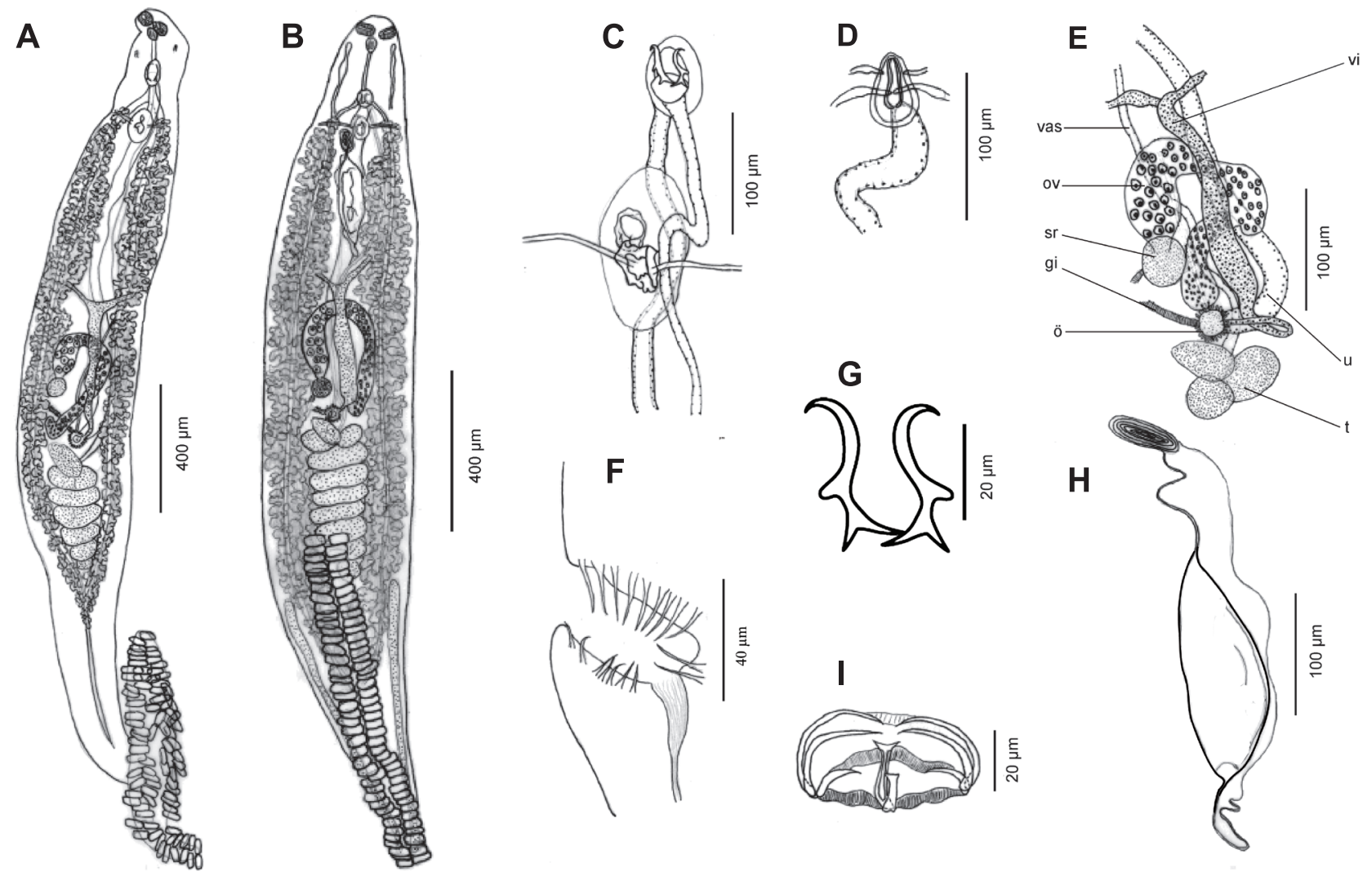

Fig. 3. Polylabroides tonkinensis sp. n. from Acanthopagrus pacificus Iwatsuki, Kume et Yoshino. A - holotype (total view); B - paratype, (total view); $\mathbf{C}$ - cirrus and vagina (ventral view); D - cirrus (lateral view); $\mathbf{E}$ - reproductive system; $\mathbf{F}$ - vaginal aperture; $\mathbf{G}$ cirrus spines; H - egg; I - clamp. Abbreviations: gi - genito-intestinal canal; ö - oötype; ov - ovary; sr - seminal receptacle; $\mathrm{t}$ - testis; $\mathrm{u}$ - uterus; vas - vas deferens; vi - duct of vitelline reservoir.

Clamps of typical Microcotyle-type without accessory sclerite (Figs. 3I, 4C), similar in shape, dissimilar in size; largest clamps in middle region of haptor, 54-63 $\times 29-31$ $(58 \times 30 ; \mathrm{n}=12)$; anterior clamps $38-50 \times 26-28(46 \times 29$; $\mathrm{n}=12)$; posterior clamps $25-36 \times 23-25(29 \times 24 ; \mathrm{n}=12)$.

Two buccal suckers, muscular, oval, without septa, $38-58 \times 36-52(50 \times 46)(\mathrm{n}=38)$. Mouth ventrosubterminal; pharynx subglobular, $30-40(36 ; n=20)$ in diameter. Oesophagus slender, without lateral diverticula, 115-212 $(171 ; \mathrm{n}=16)$ in length, bifurcating at posterior end of cirrus, about $186-282(254 ; \mathrm{n}=16)$ from anterior extremity. Intestinal caeca two, extending posteriorly but not entering haptor; right and left caecum equal in length.

Testes 7-14 $(10 ; n=16)$, postovarian, globular or elongate-oval, large, dissimilar in size, biggest testis in middle of testicular region $87-220 \times 68-120(145 \times 95)$ smallest testis in posterior or anterior end of testicular region 64-123 × 56-101 $(87 \times 77)$; arranged in longitudinal row. Vas deferens dilating with sperm at base, winding sinuously forward along midline of body, and entering posterior end of cirrus. Genital atrium situated near intestinal bifurcation, thin-walled, oval, $62-72 \times 40-47(68 \times 44 ; n=16)$. Cirrus spherical, $27-40 \times 27-41(35 \times 31 ; \mathrm{n}=16$ armed with two large spines, $28-43(34 ; \mathrm{n}=16)$ in length. Each cirrus spine sickle-shaped, with a noticeable knob and forked base forming two deep roots (Figs. 3G, 4A).

Ovary pretesticular, question mark-shaped, intercaecal, just equatorial; distal end leading to rounded seminal recep- tacle, and short duct to genito-intestinal canal connecting with oötype. Oötype posterior to ovary, oval, surrounded by Mehlis'glands (Fig. 3E). Vaginal aperture oval, median, ventral, post-bifurcal, $54-56 \times 30-32(55 \times 31 ; \mathrm{n}=12)$. Two vaginal ducts from lateral regions of vaginal aperture extending backwards and embracing intestinal caeca, connecting dorsally, travelling backward and opening into branches of vitelline duct; part of vaginal ducts connected with vaginal aperture sclerotised, about 14 in width; vaginal aperture armed with small sclerotised spine (Figs. 3F, 4B). Vitellarium follicular, coextensive with caeca; vitelline reservoir Y-shaped, common duct joins oötype. Uterus arising from dextral margin of oötype, extending sinuously forward and opening at vaginal aperture. Eggs ovoid, $179-235 \times 56-80(200 \times 68 ; n=8)$, with filaments at both ends; filament at one end extremely long and coiling in a knot (Figs. 3H, 4D).

Type host: Acanthopagrus pacificus Iwatsuki, Kume et Yoshino.

Type locality: Gulf of Tonkin, off Mong Cai district, Quang Ninh province, Vietnam, $21.446389^{\circ} \mathrm{N}, 107.943889^{\circ} \mathrm{E}$. Site of infection: Gills.

Prevalence and intensity of infection: $35 \%(18$ of 52 examined fish); and 1-16, specimens fish.

Type material: Holotype (NMH-Microcotylid-2018-3) and 10 paratypes (NMH-Microcotylid-2018-4-6; NMH-Microcotylid-2013-16-17; NMH-Microcotylid-2015-26-29; NMH-Microcotylid-2017-36-37) are deposited in the Depart- 

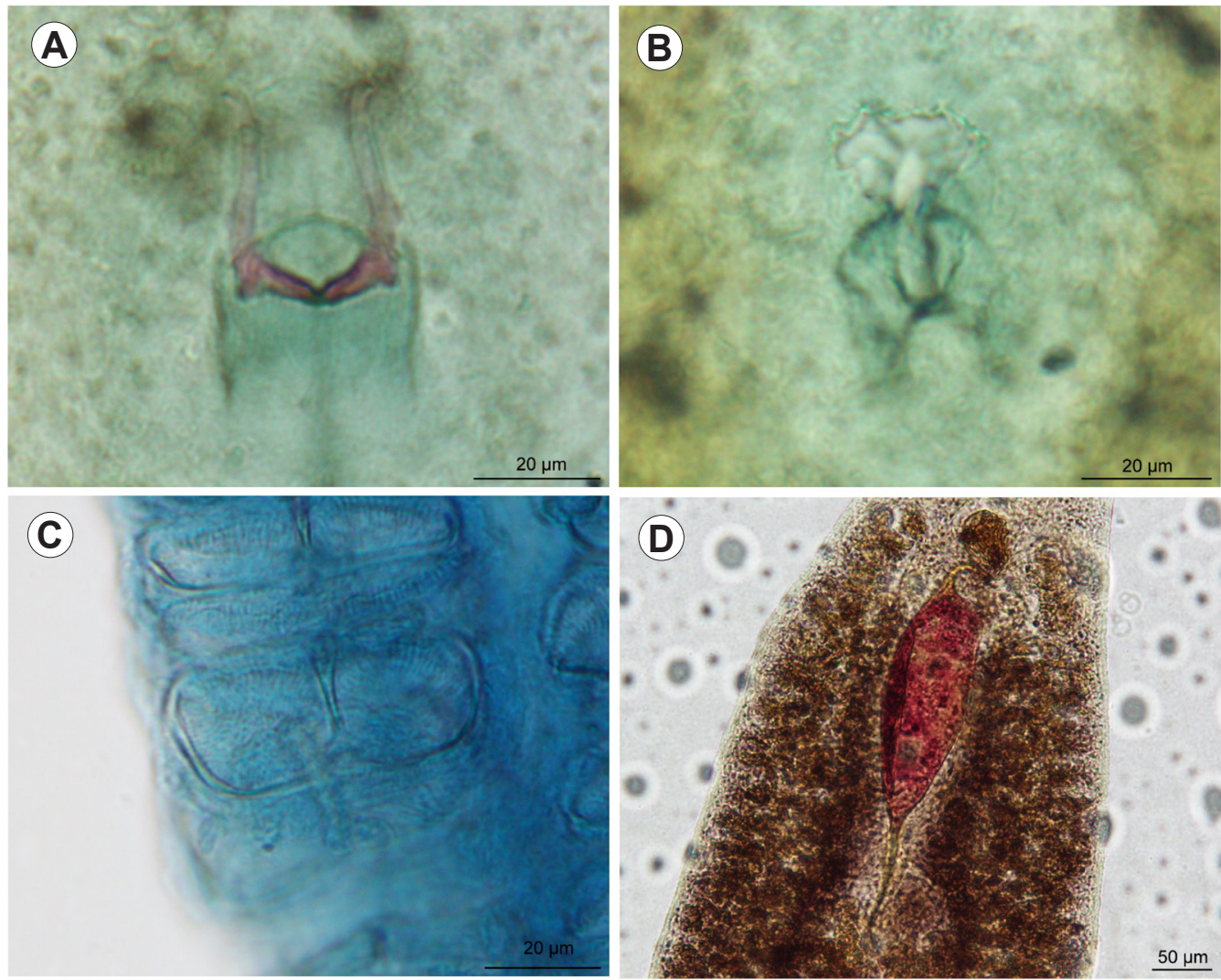

Fig. 4. Polylabroides tonkinensis sp. n. from Acanthopagrus pacificus Iwatsuki, Kume et Yoshino. A - cirrus spines (specimen stained with Mayer's carmine); B - vaginal aperture (specimen stained with Mayer's carmine); C - clamps (specimen stained with Gomori's trichrome); D - egg (specimen stained with Mayer's carmine).

ment of Parasitology, Institute of Ecology and Biological Resources; other paratypes (NMH - Microcotylid - $2018-7-15$; NMH - Microcotylid - $2013-18-25$; NMH- Microcotylid $2015-30-35 ; \mathrm{NMH}-$ Microcotylid - 2017-38) are deposited in in the Vietnam National Museum of Nature, Hanoi, Vietnam.

Etymology: The specific name refers to the typelocality of the parasite (Gulf of Tonkin)

Remarks. Polylabroides tonkinensis differs from P. quadruspinosus and $P$. longispinosus by the presence of two large spines on its cirrus, whereas the other two species have four or more spines. Similarly, P. tonkinensis can be distinguished from $P$. australis, $P$. biungulatus, P. mylionis, $P$. multispinosus and $P$. zini by the absence of small spines on its cirrus. Polylabroides tonkinensis is similar to $P$. guangdongensis in size, structure of the genital atrium and cirrus (no small spines; two large spines), as well as the number, size and arrangement of the testes, and size and shape of the eggs. However, $P$. tonkinensis differs in the following characteristics: slender oesophagus lacking lateral diverticula, haptor with fewer clamps (60-80 vs 96-106), and large spines of the cirrus sickle-shaped with a noticeable knob and two deep roots.

Polylabroides tonkinensis also differs from $P$. tienyenensis by the broader body ( 310 vs $246 \mu \mathrm{m})$, shape of the large spines on the cirrus (sickle-shaped, noticeable knob, and two deep roots $v s$ straight), fewer testes (10 vs 13) and larger eggs $(200 \times 68 \mu \mathrm{m} v s 50 \times 25 \mu \mathrm{m})$. This is the second
Polylabroides species described in A. pacificus from the coast of Vietnam.

\section{Metacamopia lebedevi sp. $\mathbf{n}$.}

Figs. 5, 6

\section{ZooBank number for species:}

urn:1sid:zoobank.org:act:31149169-BDD8-4160-BCBF-211160AD1009.

Description (based on one specimen stained in Mayer's carmine and one specimen stained in Gomori's trichrome)

Body L- or V-shaped, comprises four defined regions, namely forebody consisting of buccal cavity and genital apertures, twisted bulb region in middle, hindbody consisting of reproductive system, and haptor bearing clamps and hooks (Figs. 5A, 6B). Total length 1.89-2.34 mm, maximum width at twisted bulb 205-279. Elongate forebody tapering anteriorly, 918-943 long, 41-45 wide at anterior end, and enlarged at level of posterior end of cirrus, 66-98 wide. Twisted bulb region 370-451 long, abruptly distends at level of its junction with forebody, and its posterior constriction. Hindbody almost same length as forebody, slightly tapering posteriorly.

Haptor asymmetrical, with two dissimilar rows of four gastrocotylid type clamps. Shorter right row 98-123 long, with equidistant pedunculate clamps, clamp size 26$40 \times 21-30(34 \times 27 ; \mathrm{n}=8)$. Left row 131-213 long, with sessile clamps, clamp size 23-29 × 29-31 $(26 \times 30 ; n=8)$. Each clamp has one pair of anterolateral sclerites, one 
A

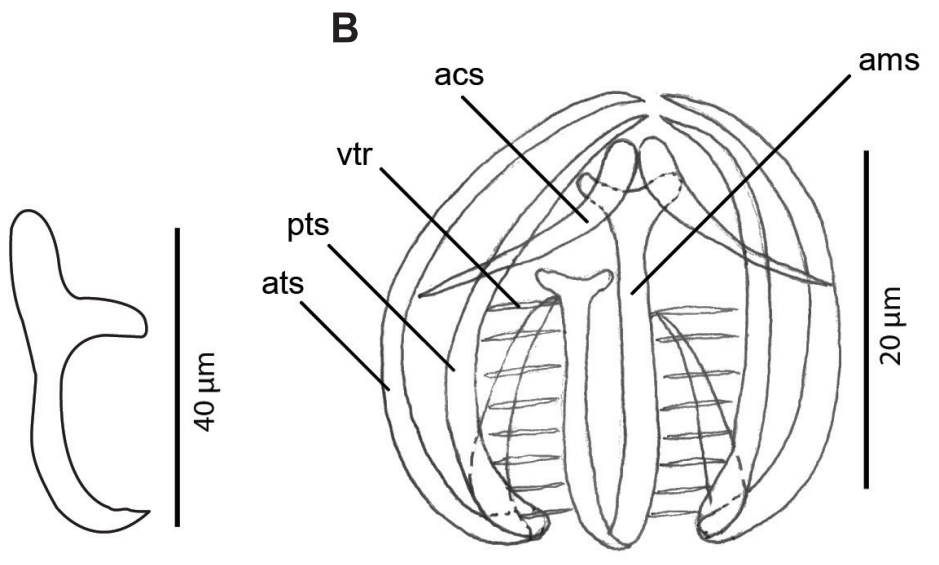

C

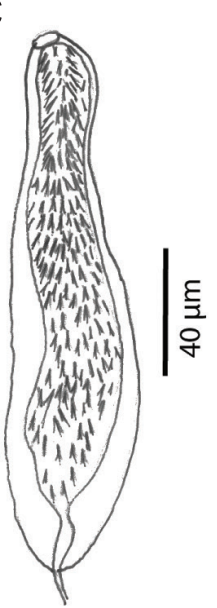

D
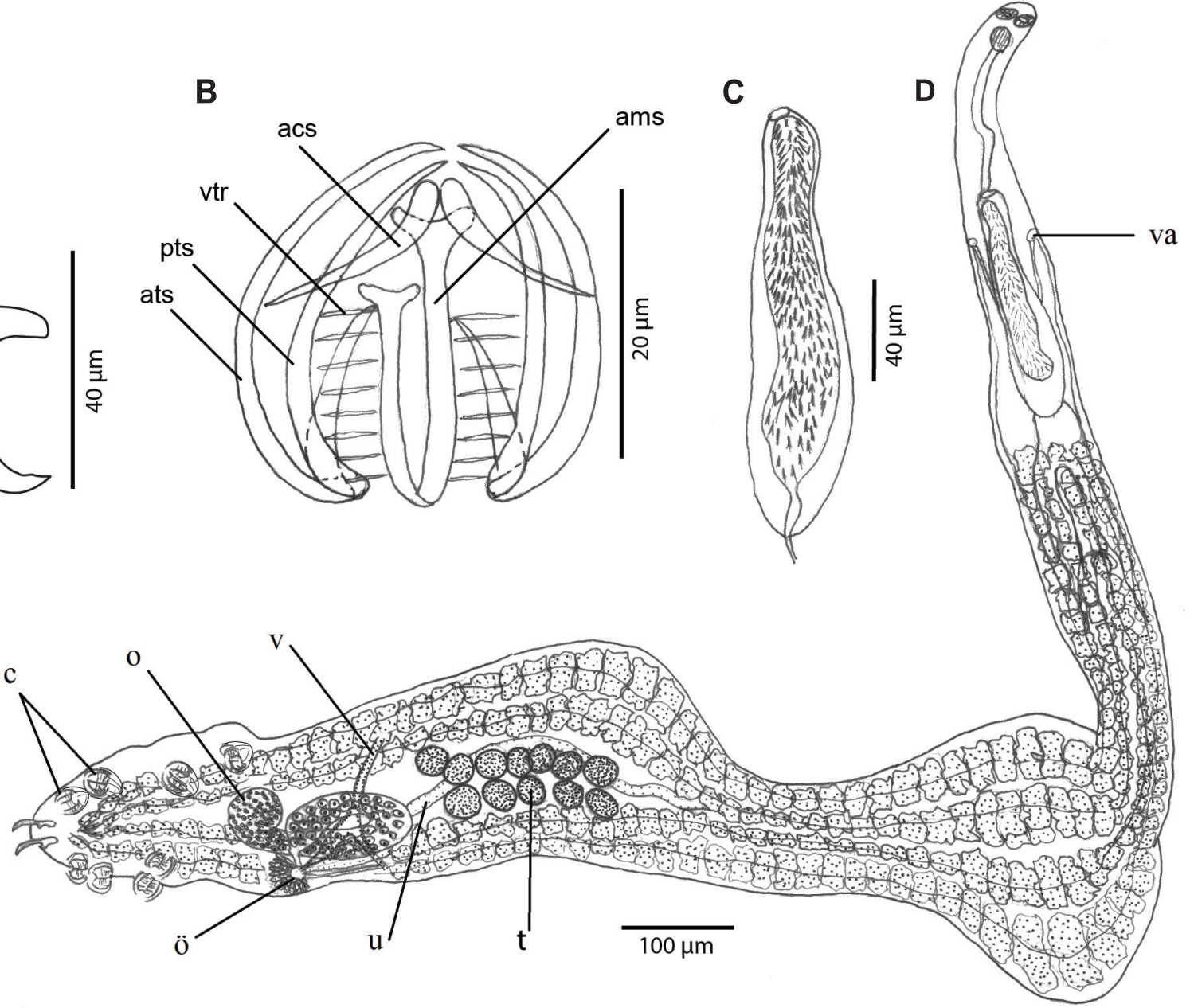

Fig. 5. Metacamopia lebedevi sp. n. from Acanthopagrus pacificus Iwatsuki, Kume et Yoshino. A - anchor; B - cirrus; C - clamp; D - holotype total view. Abbreviations: c - clamp; o - ovary; acs - accessory sclerite; ams - anterior mid-sclerite; ats - anterolateral sclerite; 0 - oötype; pts - posterolateral sclerite; $\mathrm{t}$ - testis; $\mathrm{u}$ - uterus; $\mathrm{v}$ - vaginal aperture; $\mathrm{v}$ - duct of vitelline reservoir; vtr - ventral transverse rib.
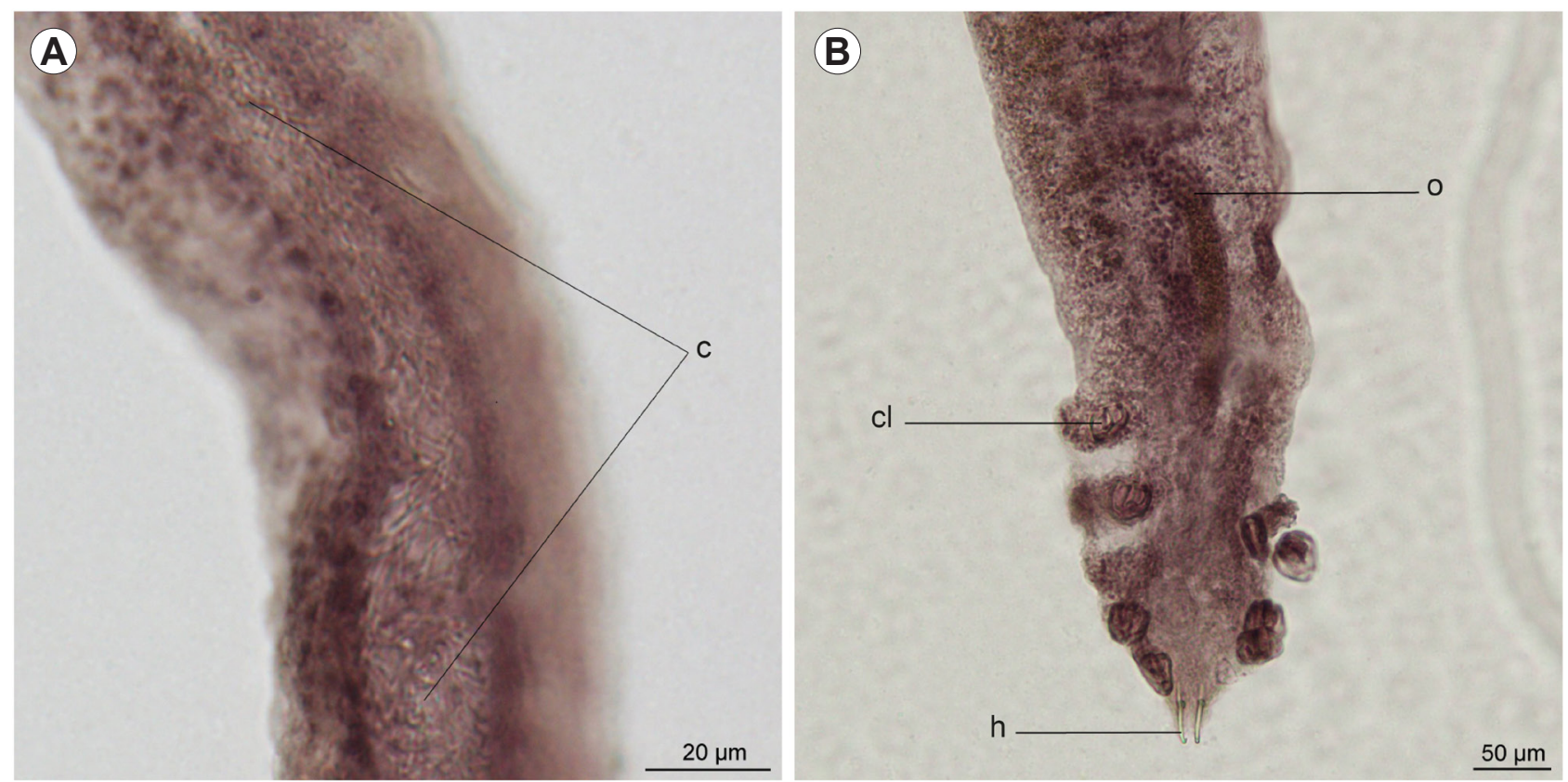

Fig. 6. Metacamopia lebedevi sp. n. from Acanthopagrus pacificus Iwatsuki, Kume et Yoshino. A - cirrus; B - posterior part. Abbreviations: $\mathrm{c}$ - small spines on the cirrus; $\mathrm{cl}$ - clamp; $\mathrm{h}$ - anchor; $\mathrm{o}$ - ovary; 
pair of posterolateral sclerites, one anterior mid-sclerite and one pair of accessory sclerites. All clamps with eight pairs of ventral transverse ribs (Fig. 5C). One pair of Haptoral anchors, 30-39 (35) long $(\mathrm{n}=4)$, sickle-shaped, with rounded base (Fig. 3D), located at terminal end of haptor.

Buccal suckers two, muscular, oval, 20-25 × 22-26 $(22 \times 24 ; n=4)$. Mouth ventro-subterminal; prepharynx absent; pharynx globular, 25 and 29 wide. Oesophagus slender, without diverticula, 492 and 496 long. Intestinal caeca two, diverticular, running along each side of body, extending posteriorly into haptor and confluent at level of the base of caudal hooks.

Testes 12, smooth, globular, 32-34 (33; $\mathrm{n}=16)$, arranged in two longitudinal intercaecal rows in anterior region of hindbody. Vas deferens winding forward in median field, slightly dilating anteriorly and joining cirrus; seminal vesicle not observed. Cirrus tubular, muscular, eversible and protrusible, $185 \times 16$ and $189 \times 41$ in size; entirely lined with numerous closely arranged conical spines (Figs. $5 \mathrm{~B}, 6 \mathrm{~A}), 4.8-5.2(5 ; \mathrm{n}=60)$ in length. Median ventral genital pore unarmed, at $189-215$ from anterior end of body.

Ovary post-testicular, question mark-shaped, placed in anterior second half of hindbody. Oötype surrounded by Mehlis' glands. Vaginal aperture two, wide, tubular, unarmed, opening laterally about 310 from anterior end of body. Two vaginal ducts leading from vaginal pores dilate into small receptacle on each side and extend posteriorly to meet in median line of intestinal bifurcation. Vitellarium follicular, co-extensive with intestinal caeca; follicles in two lateral non confluent fields extending from posterior end of cirrus to distal end of caeca. Vitelline reservoir T-shaped; median vitelline duct extending posteriorly, bending and joining oötype. Uterus arising from anterior margin of oötype, extending forwards ventrally to vas deferens and opening at common genital pore. Genitointestinal canal and eggs not observed.

Type host: Acanthopagrus pacificus Iwatsuki, Kume et Yoshino.

Type locality: Gulf of Tonkin, off Mong Cai District, Quang Ninh Province, Vietnam, $21.446389^{\circ} \mathrm{N}, 107.943889^{\circ} \mathrm{E}$.

Site of infection: gills.

Prevalence and intensity: 4\% (2 of 52 examined fish); 1 specimen/fish.

Type material: The holotype (NMH-Allodiscocotylid-2012-1) is deposited in the Department of Parasitology, Institute of Ecology and Biological Resources and paratype (NMH-Allodiscocotylid-2012-2) is deposited in the Vietnam National Museum of Nature, Hanoi, Vietnam.

Ety m o log y: The species is named in honour of Boris Lebedev from Vladivostok, Russia, for his great contribution to the classification of the Camopiinae.

Remarks. The new species is considered a member of Metacamopia due to the presence of the generic characteristics proposed by Lebedev (1972), i.e. haptor has two rows of four clamps, including pedunculated on one row and without peduncles on another row; one pair of anchors; testes preovarial in the posterior half of the body; paired dorsolateral vaginae; vaginal ducts dilated into vaginal seminal receptacles.

Only three species of Metacamopia, M. indica, Metacamopia oligoplites Takemoto, Amato et Luque, 1996, and Metacamopia chorinemi (Yamaguti, 1953), are known. The new species differs from $M$. chorinemi in the arrangement of its testes (two longitudinal rows $v s$ one row), number of anchors (one pair vs three pairs) and in having an unbranched oesophagus. Metacamopia lebedevi is smaller in size and its haptor does not have a large heel-like area, and sclerites compared with $M$. oligoplites. In addition, each clamp of $M$. lebedevi has eight pairs of ribs whereas M. oligoplites has only three pairs. Metacamopia lebedevi can be distinguished from $M$. indica in having fewer testes (12 vs 20-50) and vagina lacking sclerotised structures.

\section{Allodiscocotyla diacanthi Unnithan, 1962 Figs. 7, 8 \\ Measurements (based on one specimen stained in} Mayer's carmine).

Total length 927; maximum width across the haptor 221 . Buccal suckers $19 \times 20$; pharynx $16 \times 18$; oesophagus length 152; distance from anterior extremity to intestinal bifurcation 198. Number of testes 20, testis diameter 30; cirrus length 78, width at the anterior end 14 and maximum width at base 21 (Fig. 7A). Distance from anterior end of body to genital atrium 121 . Vaginal size $52 \times 16$. Number of clamps 8; size of clamps on the left side 49-59 × 33-35; size of clamps on the right side 55-57 $\times 43$ (Figs. 7A,D, 8). Anchor length 43 (Figs. 7A, 8).

Type host: Chorinemus sanctipetri (Cuvier) (syn. of Scomberoides lysan [Forsskål]) (Perciformes: Carangidae).

O th e r h o st s: Decapterus sp., Acanthopagrus pacificus Iwatsuki, Kume et Yoshino (new host)

Type locality: Trivandrum, India.

Other lo c a liti e s: Trivandrum, India; Madras, India, Gulf of Tonkin, Vietnam.

New locality: Gulf of Tonkin, off Do Son District, Hai Phong Province, Vietnam $\left(20.721111^{\circ} \mathrm{N}, 106.798056^{\circ} \mathrm{E}\right)$.

Site of infection: Gills.

Prevalence and intensity in Vietnam: $2 \%$ (1 of 52 examined fishes); 1 specimen.

Material: one voucher specimen (NMH-Allodiscocotylid-2012-3).

Remarks. According to the description of Unnithan (1962), Allodiscocotyla diacanthi can be identified by the presence of the morphological characteristics, such as the symmetrical haptor bearing four pairs of gastrocotylid clamps and one pair of anchors; caecal branches not confluent; testes preovarian, 15-21 in number, arranged in two intercaecal longitudinal rows; eversible cirrus Z-shaped, armed with numerous closely arranged spines; ovary inverted U-shaped; seminal receptacle and genitointestinal canal present; vitellarium follicular, coextensive with caeca; vagina muscular, unarmed.

In Vietnam, A. diacanthi was first recorded by Lebedev (1970) from Decapterus sp. (Carangidae). The Pacific seabream $A$. pacificus (Sparidae) is a new host of $A$. diacanthi. 

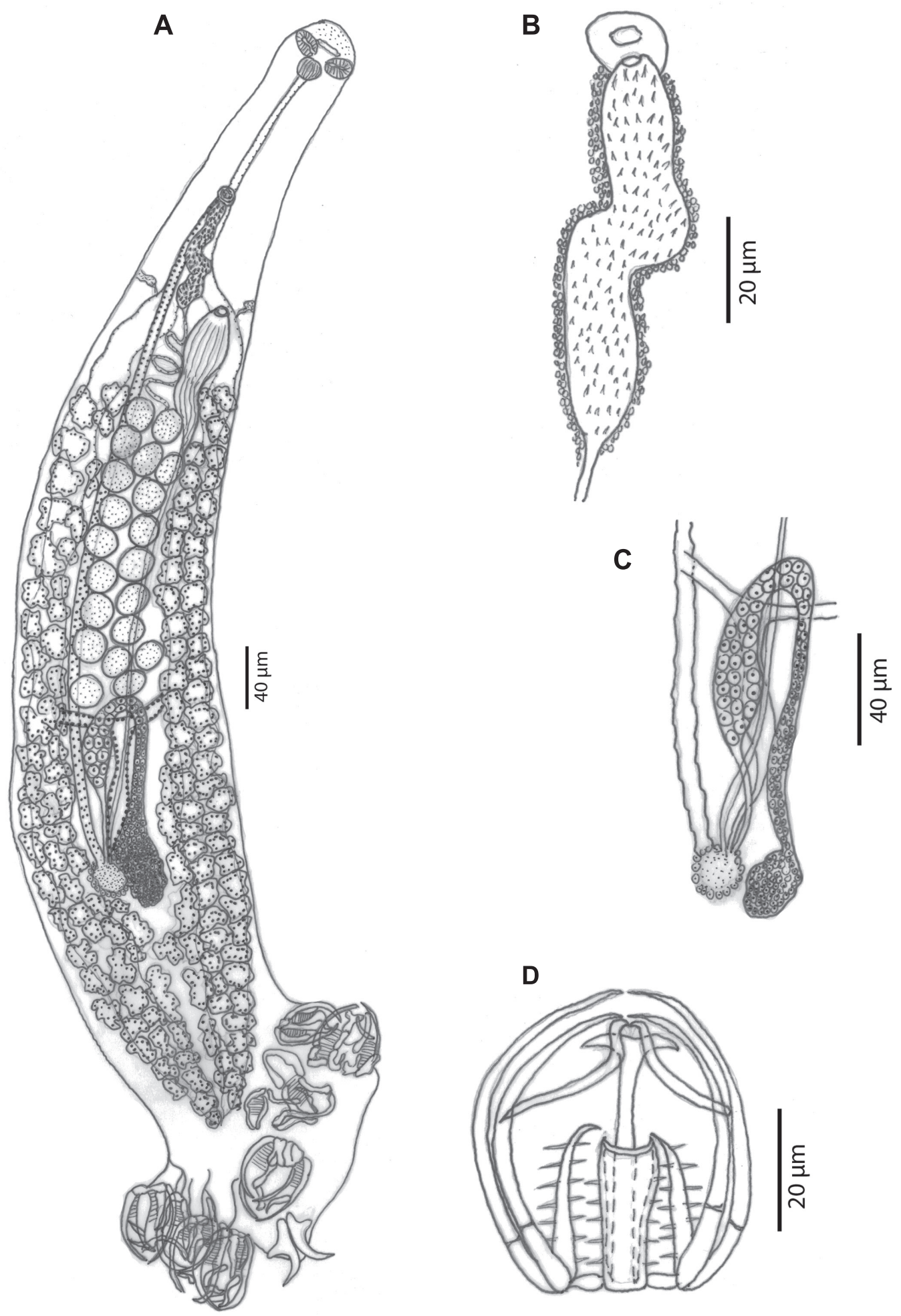

Fig. 7. Allodiscocotyla diacanthi Unnithan, 1962 from Acanthopagrus pacificus Iwatsuki, Kume et Yoshino. A - total view; B - cirrus; C - reproduce system; D - clamp.

\section{Heterapta chorinemi (Tripathi, 1956) Unnithan, 1961}

Figs. 9, 10

Measurements (based on one specimen stained in Mayer's carmine).

Total length $5.21 \mathrm{~mm}$; maximum width 369 ; length of haptor 2,808; clamps 39 pairs including 30 anterior pairs and nine posterior pairs. The biggest and smallest size of an anterior clamp $86 \times 52$ and $53 \times 49$, respectively; pos- terior clamp size 35-37 × 15-17. Buccal suckers $20 \times 18$; pharynx $22 \times 16$. Number of testes 13 , testes size $22-$ $24 \times 25-27$; large cirrus spines 2,96 in length; small cirrus spines 15 pairs, the biggest spine 24 in length. Distance from anterior end of body to genital atrium 140. Egg size $120-180 \times 50-90 ; n=8$.

Type host: Scomberoides tala (Cuvier) (Perciformes: Carangidae). 


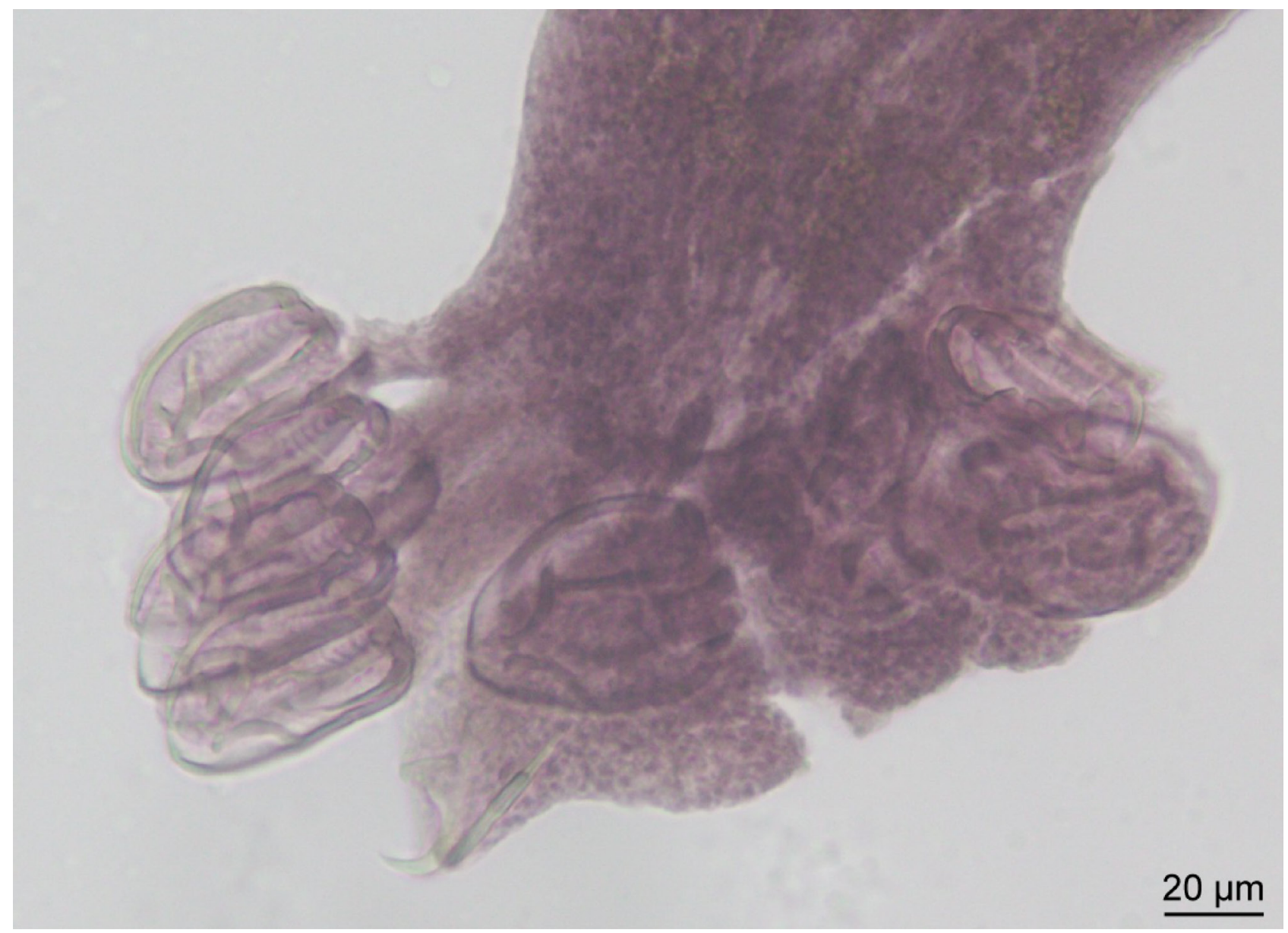

Fig. 8. Allodiscocotyla diacanthi Unnithan, 1962 from Acanthopagrus pacificus Iwatsuki, Kume et Yoshino. Haptor (specimen stained with Mayer's carmine)

New host: Acanthopagrus pacificus Iwatsuki, Kume et Yoshino Type loc ality: Mahanadi estuary, Bay of Bengal, India.

Other lo c a lite s: Mahanadi estuary, Bay of Bengal, India; Motupore Island, Papua New Guinea.

New 1 o c a lity: Gulf of Tonkin, off Giao Thuy district, Nam Dinh province, Vietnam $\left(20.207778^{\circ} \mathrm{N}, 106.413611^{\circ} \mathrm{E}\right)$.

Site of infection: Gills.

Prevalence and intensity in Vietnam: $2 \%$ (1 of 52 examined fishes); intensity: 1.

Materia 1: one voucher specimen (NMH-Heteromicrocotylid-2012-1)

Remarks. Heterapta chorinemi was described by Tripathi (1956) based on the following generic characteristics: body very long, haptor accounting for more than half of the total length of the body, bearing 39 pairs of clamps of microcotylid type, including 30 anterior pairs (opening-type) and nine posterior pairs (closing-type); testes 13 in number, arranged in two interceacal longitudinal rows, situated in the middle region of the body; the cirrus spinous with two long central spines and surrounded by 15 pairs of small spines; ovary convoluted; the vagina muscular, unarmed; the vitellarium confluent in the end of the haptor region; eggs oval with a long coiled filament at the posterior end.

The Pacific seabream is a new host record for A. diacanthi, being this study the first record of a species of Heterapta from the coast of Vietnam.

\section{DISCUSSION}

Metacamopia, which was proposed by Lebedev (1972), includes three species, i.e. Metacamopia indica, M. chorinemi and $M$. oligoplites. Takemoto et al. (1996) re-examined the type specimen of $M$. chorinemi and confirmed the presence of sclerotised structures in the vaginal ducts. The same authors described a new species, $M$. oligoplites without these structures within the vagina. In addition, they described several pairs of hooks in this species, thus greatly expanding the diagnostic characteristics of the genus. Moreover, the host of $M$. lebedevi belongs to the Sparidae, whereas the hosts of other species of Metacamopia belong to the Carangidae.

The related Vallisia Parona et Perugia, 1890 have an oesophagus with poorly differentiated diverticula as is seen in M. chorinemi. However, since there is still no satisfactory description of it, details of the distal parts of the genital ducts are unclear. However, in the figures of Vallisia striata Parona et Perugia, 1890 it is seen that the proximal parts of the vaginal ducts are markedly expanded. Metacamopia oligoplites and M. lebedevi both lack armament of the vaginal ducts. The only character that distinguishes $V$. striata from species of Metacamopia remains the rounded shape of the copulatory organ, which also needs confirmation.

Allodiscocotyla diacanthi was first described by Unnithan (1962) from the gills of Chorinemus sanctipetri (syn. of 


\section{A}

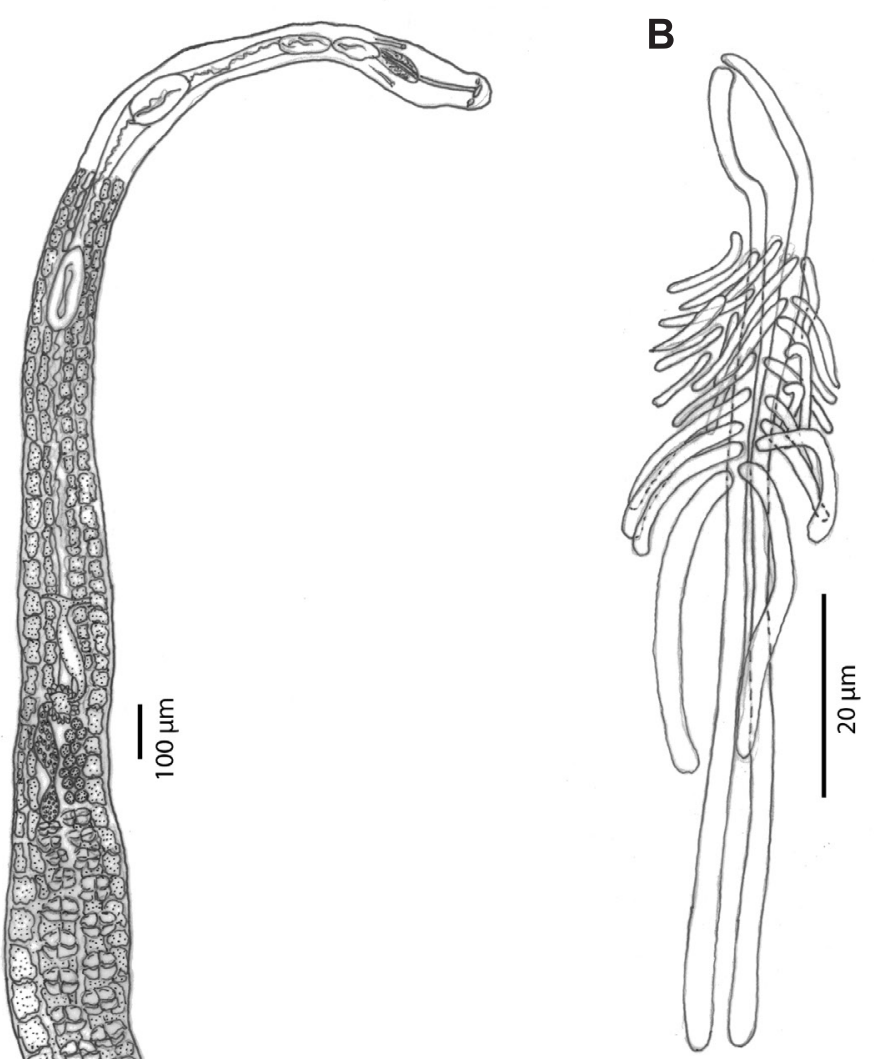

D

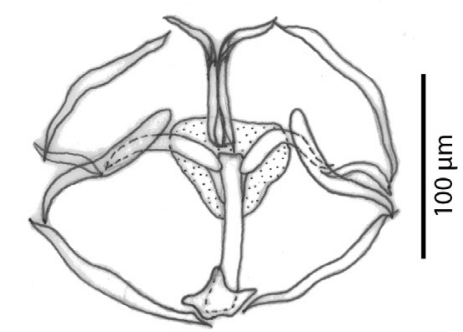

C

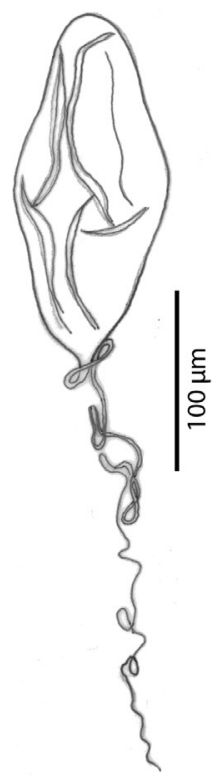

E

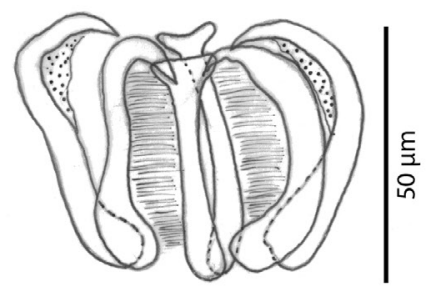

Fig. 9. Heterapta chorinemi (Tripathi, 1956) from Acanthopagrus pacificus Iwatsuki, Kume et Yoshino. A - total view; B - cirrus; C - egg; D - anterior clamp; E - posterior clamp.

Scomberoides lysan) in Trivandrum, India. Ramasamy et al. (1995) also collected $A$. diacanthi from Scomberoides tol (Cuvier) in Madras, India. The first report of A. diacanthi outside the Indian Ocean was made by Lebedev et al. (1970), who found this species in the Gulf of Tonkin, Vietnam, from the gills of Decapterus sp. However, the authors did not provide measurements. Remarkably, all previous host species of $A$. diacanthi belong to the Carangidae, whereas our present study found it in a new host species, Acanthopagrus pacificus, a member of the Sparidae.

Heterapta chorinemi was first described as Diplasiocotyle chorinemi by Tripathi (1956) from Scomberoides tala in the Bay of Bengal, India. This species was transferred to another genus, Tripathia, by Yamaguti (1963) and finally to Heterapta by Unnithan (1961). Rohde (1979) found $H$. chorinemi on the gills of the same host species from Motupore Island, Papua New Guinea. Later Ramasamy and Hanna (1986) collected this species from the gills of Scomberoides commersonianus Lacepède. Both recorded host species belong to the Carangidae. In the present study, H. chorinemi was collected for the first time from A. pacificus (Sparidae) in Vietnam.

Both families, Sparidae and Carangidae, belong to the superorder Actinopterygii, and both used to belong to the Perciformes. However, Carangidae was moved to a separate order Carangiformes. Additionally, according to a 

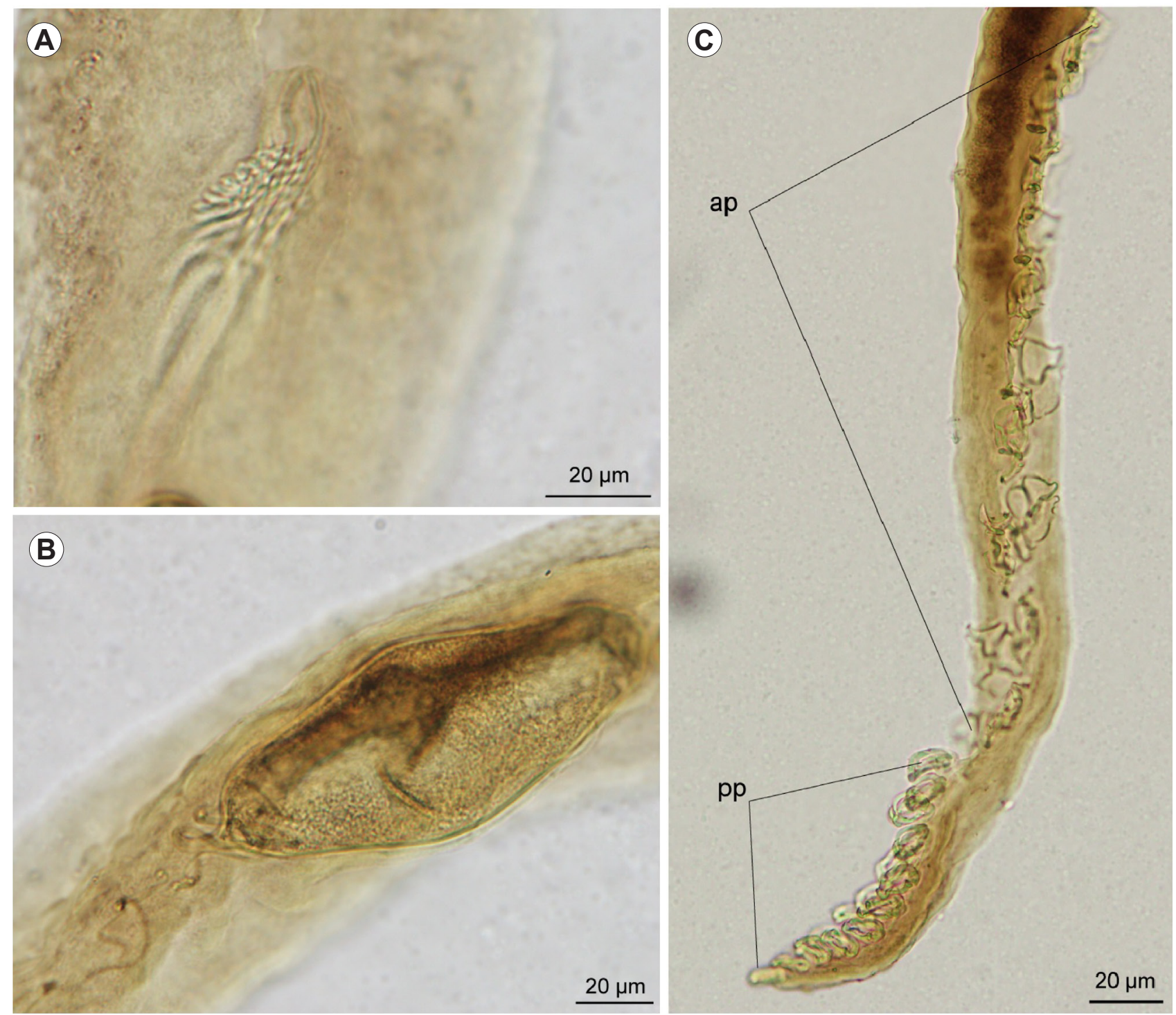

$0 \mu \mathrm{m}$

Fig. 10. Heterapta chorinemi (Tripathi, 1956) from Acanthopagrus pacificus Iwatsuki, Kume et Yoshino. A - cirrus; B - egg; C - posterior end. Abbreviations: ap - anterior clamps; pp - posterior clamps).

phylogenetic analysis based on cytochrome b mtDNA sequences, the sparidae and Carangidae are fairly divergent from each other (Nelson 2006). Although these two fish families are phylogenetically distant from each other, it is possible that they share some similarities. The host in our study, A. pacificus, is widely distributed and shows region- and site-specific ecology, especially associated with its diet. Given that we only found two specimens of $M$. lebedevi and one specimen each of $A$. diacanthi and H. chorinemi on A. pacificus in our study, it cannot be ruled out that these are incidental infections. However, in each circumstance, the parasites were fully mature adults. Future sampling efforts focused on A. pacificus are needed to further clarify these host associations.

The present study is the first record a species of Polylabroides on A. pacificus from the coast of Vietnam with the description of two new species, increasing the number of species in the genus to ten. All Polybabroides spp. are currently found to only infect members of the Sparidae. A key to five known species of Polylabroides was first proposed by Byrnes (1985). The key was expanded to include seven taxa when Mamaev (1988) described a new species, $P$. zini, and, included P. mylionis which was described by Dillon et al. (1985). The major characters for identification were the shape and number of the small and large spines on the cirrus. Subsequently, Zhang and Yang (2001) added Polylabroides guangdongensis from three fish species; Sparus macrocephalus (Basilewsky), Acanthopagrus latus (Houttuyn), and Acanthopagrus berda (Forsskål) off Guangdong, China. According to the description of $P$. guangdongensis, small spines on the cirrus are absent, as well as in the new species Polylabroides tienyenensis and Polylabroides tonkinensis described herein. Zhang and Yang (2001) suggested that the reference to small spines on the cirrus in the diagnosis of Polylabroides should be changed to present or absent. Based on the old key and characters of the species recently described, we propose a new key for all species of Polylabroides:

1. Cirrus armed with two large spines............................... 3

Cirrus armed with four or more large spines ................... 2 
2. Large spines four; small spines 35-36P. quadruspinosus Large spines 40-67; small spines 25-35 P. longispinosus 3. Small spines on the cirrus absent ................................ 4 Small spines on the cirrus present............................... 6 4. Large spines sickle-shaped with a noticeable knob and forked base P. tonkinensis

Large spines two, straight, curving at the distal end....... 5

5. Clamps 96-106 in number; eggs large $205 \times 68 \mu \mathrm{m} . .$. P. guangdongensis

Clamps 62-72 in number; eggs small $50 \times 25 \mu \mathrm{m}$

P. tienyenensis

6. Genital atrium and vagina with strong musculature; cirrus armed with a pair of large claw-like spines and 6-7 small triangulate spines; testes 13-17 in number.

P. biungulatus

Genital atrium and vagina with no developed musculature; testes up to 13 in number.. ... 7

7. Large spines shaped as roe-deer antlers; one pair of small sharp spines between them P. zini

Large spines claw-like .... 8

8. Small spines $8-10$, different in size and shape

P. australis
Small spines similar in size and form 9

9. Small spines eight in number, 9-13 $\mu \mathrm{m}$ long; large spines 23-33 $\mu \mathrm{m}$ long; testes 6-9

P. mylionis

Small spines 30-45 in number; large spines 18-26 $\mu \mathrm{m}$ long; testes 10-13.... P. multispinosus

Acknowledgements. We would like to thank Klaus Rohde from University of New England, Australia, Alex V. Ermolenko, Department of Parasitology, Federal Scientific Center of the East Asia Terrestrial Biodiversity, Far Eastern Branch, Russian Academy of Sciences, Vladivostok, Russia and Huy Phong Dang, Institute of Ecology and Biological Resources, Vietnam Academy of Science and Technology for providing literature; Delane C. Kritsky from Idaho State University for providing useful comments. We also appreciate the valuable contributions of the anonymous reviewers. This study was funded by the National Programs (VAST.DA47.DA.12/16-19) with the project title "Investigation and evaluation of the parasites and microorganisms in the marine areas of Vietnam with the aims to protect marine ecosystems and public health". One part of samples provided by the project "Research on developing a model of green economy for some typical island communes in Vietnam coastal areas - KC.08.09/16-20".

\section{REFERENCES}

Al-Daraji S.A.M., Bannai M.A.A., Abbas A.A.K. 2010: Some parasites of the yellow-finned sea bream Acanthopagrus latus (Houttuyn, 1782) in the Iraqi marine water. Iraqi J. Aquacult. 7: $115-122$.

Byrnes T. 1985: Four species of Polylabroides (Monogenea: Polyopisthocotylea: Microcotylidae) on Australian bream, Acanthopagrus spp. Austr. J. Zool. 33: 729-742.

Byrnes T. 1986a: Five species of Monogenea from Australian bream, Acanthopagrus spp. Austr. J. Zool. 34: 65-86.

Byrnes T. 1986b: Six species of Lamellodiscus (Monogenea: Diplectanidae) collected from Australian bream (Acanthopagrus spp.). Publ. Seto Mar. Biol. Lab. 31: 169-190.

Chauhan B.S. 1945: Trematodes from Indian marine fishes part I. On some new monogenetic trematodes of the sub-orders monopisthocotylea Odhner, 1912 and polyopisthocotylea Odhner, 1912. Ind. Acad. Sci. Sect. B 21: 129-159.

Dillon W.A., Hargis W.J., Harrises A.E. 1985: Monogenetic trematodes from the Southern Pacific Ocean. Polyopisthocotyleids from the Australian fishes, the subfamily Polylabrinae and Microcotylinae. Parazitol. Sb. 33: 83-87. (Translation series number 33 of the Virginia Institute of Marine Science, the College of William and Mary, Virginia, 1987).

Hussey C.G. 1986: Some monogenean parasites of marine perciform fishes of Kuwait. J. Nat. Hist. 20: 415-430

Iwatsuki Y., Kume M., Yoshino T. 2010: A new species, Acanthopagrus pacificus from the Western Pacific (Pisces, Sparidae). Bull. Natl. Mus. Nat. Sci. Ser. A Zool. 36: 115-130.

Johnston T.H., Tiegs O.W. 1922: New gyrodactyloid trematodes from Australian fishes, together with a reclassification of the supper family Gyrodactyloidea. Proc. Linn. Soc. N.S.W. 47: 83-131.

Ko R.C., Chan. W. 2002: A Preliminary Study on the Parasite Fauna of Three Common Marine Fish of Hong Kong (Siganus fuscescens, Sebasticus marmoratus, Epinephelus akaara). The University of Hong Kong Occasional Publication, Hong Kong, $71 \mathrm{pp}$.

KRITSKY D.C. 2012: Dactylogyrids (Monogenoidea: Polyonchoinea) parasitizing the gills of snappers (Perciformes: Lutjanidae) revision of Euryhaliotrema with new and previously described species from the Red Sea, Persian Gulf, the eastern and In- do-west Pacific Ocean, and the Gulf of Mexico. Zoologia 29: 227-276.

Kritsky D.C., Boeger W.A. 2002: Neotropical Monogenoidea. 41: New and previously described species of Dactylogyridae (Platyhelminthes) from the gills of marine and freshwater perciform fishes (Teleostei) with proposal of a new genus and a hypothesis on phylogeny. Zoosystema 24: 7-40.

LEBEDEV B.I. 1970: [Helminths of epipelagic fishes of the South China Sea]. In: B.I. Lebedev, Y.L. Mamaev and P.G. Oshmarin (Eds.), Helminths of Animals of South-Eastern Asia. Nauka, Moscow, pp. 191-216. (In Russian.)

LEBEDEV B.I. 1972: [Taxonomy of the monogeneans of the suborder Gastrocotylinea]. Proc. Inst. Biol. Ped., Far East Branch of the USSR Academy of Sciences, Vladivostok 11: 121-145. (In Russian.)

Lebedev B. I. 1986: [Monogenoidea, Suborder Gastrocotyline]. Nauka, Leningrad, 200 pp. (In Russian.)

Lebedev B.I., Parukhin A.M., Roitman V.A. 1970: [Monogenetic trematodes, Oligonchoinea (Monogenoidea), parasites of horse mackerel fishes of North Vietnam Gulf]. Biol. Morya 20: 167-187. (In Russian.)

Mamaev Y.L. 1988: Polylabroides zini sp. n., a new species of higher monogenean from a marine fish, Acanthopagrus latus. Helminthologia 25: 195-200.

Mamaev Y.L., Parukhin A.M. 1976: [On the genus Polylabris Euzet et Cauwet, 1967 and some closely allied species of Microcotylids (Monogenoidea: Microcotylidae)]. Parazitologiya 10: 245-254 (In Russian.)

Maran B.A., OH S.Y., Moon S.Y., Soh H.Y., Kim C.W., Myoung J.G. 2014: Monogeneans (Platyhelminthes) from marine fishes of Tongyeong, Korea. J. Parasit. Dis. 38: 277-285.

Murray F.V. 1931: Gill trematodes from some Australian fishes. Parasitology 23: 492-506.

Nelson J.S. 2006: Fishes of the World. Fourth edition. John Wiley and Sons, Inc., New York, 624 pp.

Nitta M., Nagasawa K. 2015: A check list of monogeneans (Platyhelminthes) parasitic on fishes and invertebrates of the Seto Inland Sea, Japan (1894-2015), with new locality records for 
Anoplodiscus spari (Anoplodiscidae) and Dactylogyryus gotoi (Dactylogyridae). Bull. Hiroshima Univ. Mus. 7: 117-127.

Ogawa K., Egusa S. 1978a: Haliotrema kurodai sp. n. (Monogenea: Dactylogyridae, Aencyrocephalinae), a monogenean parasite obtained from the Japanese black sea bream, Acanthopagrus schlegelii (Bleeker). Bull. Jpn. Soc. Sci. Fish. 44: 13291332.

Ogawa K., Egusa S. 1978b. Three species of Lamellodiscus (Monogenea: Diplectanidae) from the gills of the Japanese black sea bream, Acanthopagrus schlegelii (Bleeker). Nippon Suisan Gakk. 44: 607-612.

Ogawa K., Egusa S. 1980: Two species of microcotylid monogeneans collected from black Sea bream, Acanthopagrus schlegelii (Bleeker) (Teleostei: Sparidae). Jpn. J. Parasitol. 29: 455-462.

Ogawa K., Egusa S. 1981: The systematic position of the genus Anoplodiscus (Monogenea: Anoplodiscidae). Syst. Parasitol. 2: 253-260.

Ramasamy P., BRenNan G.P., Halton D.W. 1995: Ultrastructure of the surface structures of Allodiscocotyla diacanthi (Polyopisthocotylea: Monogenea) from the gills of the marine teleost fish, Scomberoides tol. Int. J. Parasitol., 25: 43-54.

Ramasamy P., Hanna R.E.B. 1986: The surface topography of a monogenean Heterapta chorinemi from the gills of Scomberoides scomberoides. Int. J. Parasitol. 16: 595-600.

RoHDE K. 1979: Monogenean gill parasites of some marine fishes of Papua New Guinea. Zool. Anz. 203: 78-94.

Roubal F.R. 1981: The taxonomy and site specificity of the metazoan ectoparasites of the BlackBream, Acanthopagrus australis (Güther) in Northern New South Wales. Aust. J. Zool. (Suppl. s.) $84: 1-100$.
Tакемото R.M., Амato J.F.R., LuQue J.L. 1996: Monogeneans of leatherjackets, Oligoplites spp. (Osteichthyes: Carangidae), with the description of a new species of Metacamopia (Monogenea: Allodiscocotylidae) from the coast of the state of Rio de Janeiro, Brazil. Mem. Inst. Oswaldo Cruz 91: 165-172.

Tripathi Y.R. 1956: Studies on the parasites of Indian fishes IV. Trematoda: Monogenea, Microcotylidae. Rec. Ind. Mus. 52: 231-248.

UnNithan R.V. 1961: On the functional morphology of a new fauna of Monogenoidea on fishes from Trivandrum and environs. Part III. Heteromicrocotylidae (Microcotyloidea). Ind. J. Helminthol. 8: 112-145.

UNNITHAN R.V. 1962: On the functional morphology of a new fauna of Monogenoidea on fishes from Trivandrum and environs. Part II. Opisthogynidae fam. nov. (Gastrocotyloidea) and Abortipedinae subfam.nov. (Protomicrocotyloidea). Parasitology 52: $315-351$.

Yamaguti S. 1934: Studies on the helminth fauna of Japan. Part 2. Trematodes of fishes, I. Jpn. J. Zool. 5: 249-541.

Yamaguti S. 1958: Studies on the helminth fauna of Japan. Part 53. Trematodes of fishes, XII. Publ. Seto Mar. Biol. Lab. 7: 53-88.

Yamaguti S. 1963: Systema Helminthum: Vol. IV. Monogenea and Aspidocotylea. Interscience Publishers, London, $699 \mathrm{pp}$.

Zhang D., Li W.X., Zou H., Wu S.G., Li M., Jakovlic I., Zhang J., Chen R., Wang G.T. 2018: Mitochondrial genomes of two diplectanids (Platyhelminthes: Monogenea) expose paraphyly of the order Dactylogyridae and extensive tRNA gene rearrangements. Parasit. Vectors 11: 601.

Zhang J., Yang T. 2001: Monogenea of Chinese marine fishes. XIV. Two new species of Microcotylidae from fishes of the South China Sea. Syst. Parasitol. 48: 67-73

Cite this article as: Nguyen H.V., Nguyen H.M., Ha N.D., Ngoc C.N., Ngoc T.B., Le S.X., Tatonova Y., Greiman S.E. 2020: Five monogenean species (Allodiscocotylidae, Heteromicrocotylidae, Microcotylidae) from the Pacific seabream Acanthopagrus pacificus (Perciformes: Sparidae) in the Gulf of Tonkin off Vietnam, with descriptions of three new species. Folia Parasitol. 67: 028. 